\title{
Relationship between pre-operative bleeding and perforation and bleeding after operations for duodenal ulcer
}

\author{
M. J. S. LANGMAN ${ }^{1}$ \\ From the Department of Medicine, Guy's Hospital, and the \\ Department of Gastroenterology, Central Middlesex Hospital, London
}

EDITORIAL SYNOPSIS The results of this study of 100 patients bleeding after a definitive operation for duodenal ulcer matched with unselected controls demonstrates statistically a long-suspected clinical fact that such patients have a special tendency to bleed before operation.

Bleeding from a proved or probable stomal ulcer at some time after an operation for peptic ulceration often seems to be preceded by haemorrhage from the original, usually duodenal, ulcer. This association has been noted in the past (Hurst and Stewart, 1929; Donaldson, Handy, and Papper, 1958), but satisfactory evidence in its favour is lacking.

The case histories of patients admitted to the Central Middlesex Hospital with bleeding following an operation for duodenal ulceration have therefore been reviewed and the frequencies of both preoperative haemorrhage and perforation in this test group have been compared with those in a control group of an unselected consecutive series of operations for duodenal ulcer.

\section{METHOD}

Detailed records are kept of all admissions to the Central Middlesex Hospital for acute upper gastro-intestinal haemorrhage. From this material all cases admitted from 1950 to 1962 with bleeding at some time after an operation for duodenal ulceration have been selected. A firm diagnosis of stomal ulceration was not required for

${ }^{1}$ Present address: M.R.C. Statistical Research Unit, 115 Gower Street, London, W.C.1. inclusion; patients were also selected who showed no abnormality on barium meal or gastroscopy. For comparison a control group was taken of 1,027 duodenal ulcer operations performed between 1953 and 1962. These included all elective or emergency operations except simple suture of a perforated ulcer. The frequency of pre-operative haemorrhage and perforation was then compared in the test and control groups.

\section{RESULTS}

Table I shows the frequency of pre-operative haemorrhage and perforation in the two groups. There is a clear difference between them which is highly significant statistically, haemorrhage and perforation pre-operatively being much commoner in the post-operative bleeding cases.

Table II shows the results in the test group when broken down according to the type of operation performed. It demonstrates that both for simple gastro-enterostomy and Polya partial gastrectomy the relationship holds; this is probably particularly so for the Polya operation but numbers are insufficient for reliable deductions to be made. The remaining operative categories are so small that no conclusions can be made about them.

\section{TABLE I}

PRE-OPERATIVE HISTORY OF BLEEDING OR PERFORATED DUODENAL ULCER IN A SERIES OF POST-OPERATIVE BLEEDING CASES AND A CONTROL SERIES OF SUCCESSIVE DUODENAL ULCER OPERATIONS

$$
\text { Pre-operative History }
$$

Total Nos. Haemorrhage Perforation Haemorrhage + Pain or Obstruction
Perforation

\begin{tabular}{lccccc}
\hline Patients bleeding after gastric surgery & 100 & 33 & 21 & 7 \\
Unselected operations for duodenal ulcer & 1,027 & $202(19 \cdot 67 \%)$ & $150(14 \cdot 61 \%)$ & $38(3 \cdot 70 \%)$ \\
& $x^{2}=19 \cdot 2$ & $n=1$ & p $<0.001$ & $637(62 \cdot 02 \%)$ \\
& & & 134 & &
\end{tabular}


TABLE II

TYPE OF OPERATION AND PRE-OPERATIVE HISTORY IN PATIENTS BLEEDING POST-OPERATIVELY

\begin{tabular}{|c|c|c|c|c|c|}
\hline Operation & Total & Haemorrhage & Perforation & $\begin{array}{l}\text { Haemorrhage }+ \\
\text { Perforation }\end{array}$ & Pain or Obstruction \\
\hline Simple gastroenterostomy & 56 & 16 & 13 & 5 & 22 \\
\hline Gastroenterostomy and vagotomy & 4 & 1 & - & - & 3 \\
\hline Billroth I gastrectomy & 9 & 1 & 3 & 1 & 4 \\
\hline Polya gastrectomy & 27 & 14 & 5 & 1 & 7 \\
\hline Uncertain & 4 & 1 & - & - & 3 \\
\hline Totals & 100 & 33 & 21 & 7 & 39 \\
\hline
\end{tabular}

Although a highly significant statistical difference exists between the control and test groups it is possible that this could be an artefact. The control group covers the operative period 1953-62 whereas many of the test group cases were operated upon in the previous two decades, and at other hospitals where surgical criteria may differ.

Table III shows that the proportion of control group operations performed on patients with a history of haematemesis or perforation was highest in 1953-55; if this rise persisted in earlier years then any difference between control and test groups would have been exaggerated. Jamieson (1955) and Weir (1960) have both suggested that the incidence of perforated ulcer varies over the years, and presumably the same could be true of bleeding. But examination of their figures shows a steady rise in incidence of perforation to a peak in 1953-54, apart from a short-lived sharp increase in 1940-41. The general rise with time might be due to an increased frequency of perforation compared with other symptoms such as pain, or it might reflect a change in incidence of peptic ulceration whatever the symptoms, but it still does not preclude the possibility that surgeons in the past were more inclined

TABLE III

PROPORTION OF PATIENTS WITH PERFORATION OR HAEMORRHAGE IN THEIR HISTORY OPERATED UPON IN 1953-62

\begin{tabular}{ccc} 
Year & Total & No. with Haemorrhage/Perforation \\
\hline 1953 & 91 & $45(49 \cdot 5 \%)$ \\
1954 & 116 & $49(42 \cdot 2 \%)$ \\
1955 & 117 & $63(53 \cdot 9 \%)$ \\
1956 & 106 & $39(36 \cdot 8 \%)$ \\
1957 & 107 & $36(33 \cdot 6 \%)$ \\
1958 & 85 & $27(31 \cdot 8 \%)$ \\
1959 & 128 & $37(28.9 \%)$ \\
1960 & 119 & $43(36 \cdot 1 \%)$ \\
1961 & 84 & $25(22 \cdot 8 \%)$ \\
1962 & 74 & $26(35 \cdot 1 \%)$
\end{tabular}

TABLE IV

PRE-OPERATIVE HISTORY IN TEST GROUP ACCORDING TO DATE OF ORIGINAL OPERATION

\begin{tabular}{llc} 
Date & Total & No. with Bleeding/Perforation \\
\hline $1950-62$ & 42 & $28(66.6 \%)$ \\
Pre-1950 & 58 & $33(56.9 \%)$
\end{tabular}

to operate on ulcers with a history of perforation or bleeding. However if the cases in the test group are divided into those operated upon before and after 1950 (Table IV) it will be seen that there are more cases with a pre-operative history of haemorrhage and perforation in the later period than in the earlier, although the variation is slight. The reverse tendency might have been expected if changing operative diagnostic criteria had been the cause of the difference between test and control groups, cases before 1950 being operated upon mainly for haemorrhage or perforation and seldom for pain.

If we assume that the control group should contain $50 \%$ of cases with a previous history of haemorrhage or perforation, which is the peak figure shown in Table III about 1953-55, and from the evidence given is very likely an overstatement, then the result is still significant $\left(\chi^{2}=4.0 ; p=0.045\right)$.

Women form $21 \%$ of the control group and only $13 \%$ of the test post-operative group; furthermore their ulcers were slightly less liable to pre-operative bleeding and perforation than those of men, the figures being $29 \%$ for women and $41 \%$ for men. In fact if men alone are compared in the test and control groups $\chi^{2}=14.1$ and $\mathrm{p}<0.001$, so that any tendency towards a spurious correlation must be extremely small.

Another point which could possibly bias the results is that operations primarily for pain or obstruction might be performed early in an ulcer's course and this could prevent haemorrhage or perforation which would otherwise occur. The only reasonably objective criterion by which this possibility could be assessed is age at operation, for if it were true then painful or obstructing ulcers in the control group should show an earlier age at operation than the post-operative bleeding cases. The mean age of patients bleeding after the initial operation was 45 years, and the mean age for all patients with duodenal ulcer operated for pain or obstruction was 45.2 years in 1953-54 and 46.5 years in 1961-62. There is, therefore, very little difference in age between the groups, and any such change has not taken place with time, to any significant degree.

Taken altogether the variations described above 
may have biased the results in favour of the original hypothesis, but is seems very unlikely that they can have nullified them.

\section{DISCUSSION}

Hurst and Stewart (1929) believed that haemorrhage as a symptom after gastro-enterostomy was more frequent in the group in which the original operation was performed because of bleeding but their cases were too few to substantiate their hypothesis.

Later Ivy and Fainer (1950) collected similar information and drew the same conclusions. Their figures, which combined the results of three other groups of workers, suggested that cases with bleeding before operations were about twice as likely to have bleeding at some time after operation as cases with no bleeding beforehand. However, it is difficult to know how adequate the controls were with regard to the points mentioned earlier. Again, Donaldson et al. (1958) produced some suggestive evidence but did not include any controls for comparison.

From the present data it would seem that there is a predisposition to haemorrhage in some patients, as evidenced by their tendency to bleeding before and after operation from two different sites, the earlier episode of bleeding coming from a duodenal ulcer and the later probably from stomal ulceration.

It is also of interest that both haemorrhage and perforation are increased in approximately equal frequency in the pre-operative histories of the postoperative bleeding cases, and would perhaps suggest that the factors tending to cause haemorrhage and perforation are partially the same. A further indication that this might be true is the seasonal variation for perforated ulcer found by Jamieson (1947) and for bleeding ulcer (Breen and Grace, 1962; Langman, 1964). Figures for perforated anastomotic ulcer might support the hypothesis by showing a high pre-operative rate of haemorrhage or perforation but insufficient cases were available to investigate this point.

\section{SUMMARY}

A series of 100 cases of bleeding at some time after a definitive operation for duodenal ulcer has been surveyed. Compared with an unselected control group of operations there is a highly significant increase in the number of cases with a pre-operative history of haemorrhage or perforation: reasons are given for believing that this is a true difference.

It is a pleasure to thank Dr. F. Avery Jones, consultant physician to the Central Middlesex Hospital, and Miss Barbara White, librarian to the Department of Gastroenterology, Central Middlesex Hospital, without whose help this paper would not have been written. This work was partly carried out during the term of a grant from the Guy's Hospital Endowment Fund.

\section{REFERENCES}

Breen, F. J., and Grace, W. J. (1962). Bleeding peptic ulcer; seasonal variation. Amer. J. dig. Dis., 7, 727-732.

Donaldson, R. M., Handy, J., and Papper, S. (1958). Five year follow up study of patients with bleeding duodenal ulcer with and without surgery. New Engl. J. Med., 259, 201-207.

Hurst, A. F., and Stewart, M. J., (1929). Gastric and Duodenal Ulcer. Oxford University Press, London.

Ivy, A. C., and Fainer, D. C. (1950). Unpublished data quoted in Peptic Ulcer, by A. C. Ivy, M. I. Grossman, and W. H. Bachrach, p. 594. Blakiston, Philadelphia.

Jamieson, R. A. (1947). Perforated peptic ulcer. Brit. med. J., 2, 289-291.

(1955). Acute perforated peptic ulcer frequency and incidence in the West of Scotland, Ibid., 2, 222-227.

Langman, M. J. S. (1964). The seasonal incidence of bleeding from the upper gastro-intestinal tract. Gut, 5, 142-144.

Weir, R. D. (1960). Perforated peptic ulcer in North-East Scotland. Scot. med. J., 5, 257-264. 